\title{
A feasibility randomised controlled trial of Novel Activity Management in severe ASthma-Tailored Exercise (NAMASTE): yoga and mindfulness
}

\author{
Sarah A. Hiles ${ }^{1}$, Paola D. Urroz ${ }^{1}$, Peter G. Gibson ${ }^{1,2}$, Adam Bogdanovs $^{3}$ and Vanessa M. McDonald ${ }^{1,2^{*}}$
}

\begin{abstract}
Background: Physical inactivity is common in severe asthma and associated with poor health outcomes. New approaches are needed to address physical inactivity in this group.

Objective: To examine whether yoga and mindfulness improves health-related quality of life (HRQoL) compared with a minimal active control group and collect feasibility data to inform future studies.

Methods: Over 12-weeks, adults with severe asthma were recruited. Participants were randomised 2:1 to parallel yoga or control groups. All participants received an activity tracker. The yoga group received tailored group classes twice a week for 16-weeks with a qualified yoga instructor. The control group set activity goals with a research officer and received eight progress calls. Outcomes were assessed at 16-weeks. Primary outcome was St George's Respiratory Questionnaire (SGRQ). Secondary outcomes included asthma control, physical activity, breathlessness, and inflammation. Face-to-face qualitative interviews were conducted to determine acceptability.

Results: There were 15 participants randomised to yoga (mean 67 years; 60\% female) and 9 to control (68 years; 56\% female). Planned comparisons indicated the yoga group had greater SGRQ improvement than the control group. There was little change in secondary outcomes. Moderate-vigorous activity increased substantially in the control group. Participants found the intervention acceptable; key barriers and facilitators were social connection, the setting, addressing breathing and asthma symptoms, changing their mindset, and the intersection of different elements.
\end{abstract}

Conclusion: A yoga and mindfulness intervention was feasible, acceptable to patients and improved HRQoL. The findings will inform design of much needed future research into physical activity interventions for severe asthma.

World Health Organization International Clinical Trials Registry Platform The study was registered under the Australian New Zealand Clinical Trials Registry (ANZCTR) on the 26th of November 2018, Trial ID ACTRN12618001914257.

Keywords: Severe asthma, Yoga, Mindfulness, Asthma management, Health-related quality of life, Exercise, Physical activity, Sedentary

*Correspondence: vanessa.mcdonald@newcastle.edu.au

${ }^{1}$ Centre of Excellence in Severe Asthma and Priority Research Centre for Healthy Lungs, University of Newcastle, University Drive, Callaghan, NSW 2308, Australia

Full list of author information is available at the end of the article

\section{Introduction}

People with severe asthma have a range of comorbidities and risk factors that worsen prognosis and impair quality of life [1]. Physical inactivity and sedentary behaviour are common and largely ignored, with few studies characterising these behaviours and fewer interventions targeting 
activity in severe asthma [2,3]. Physical inactivity is associated with negative health outcomes, including obesity, anxiety and depression, which are common comorbidities in severe asthma $[1,3,4]$. To date there have been no targeted interventions for people with severe asthma to simultaneously address these multiple risk-factors.

Given the benefits of physical activity in healthy populations $[5,6]$, asthma $[7,8]$ and COPD $[9,10]$, it is likely that increasing physical activity and reducing sedentary time will lead to improved outcomes for people with severe asthma. However, this can be complex in severe asthma as exercise can increase symptoms and lead to fear of exercising and increased sedentary behaviour [10]. Yoga is a mind-body practice that involves breathing, postures and stretches, and meditation. These practices have demonstrated health benefits, particularly for cardiometabolic and mental health [11, 12]. Although high quality studies are lacking, evidence suggests that yoga and mindfulness have positive effects on asthma-related quality of life when compared with usual care in mild to moderate disease, with mixed or limited evidence as to whether yoga influences spirometry, biomarkers or asthma control [13-15]. Typically, people with severe asthma have been excluded from these studies, yet this population have the greatest deficits in quality of life and most to gain.

The primary aim of this study was to investigate whether tailored yoga and mindfulness classes improve health-related quality of life of people with severe asthma, compared with a minimal active control group focused on physical activity goal-setting. We also aimed to investigate the intervention's feasibility and acceptability from the patients' perspective, and its effect on other important clinical outcomes, including physical activity, breathlessness, symptoms of anxiety and depression, sleep quality and systemic inflammation. We hypothesised that yoga and mindfulness classes will lead to significant improvements in health-related quality of life and other important clinical outcomes.

\section{Methods \\ Design}

This was a single-centre parallel-group pilot randomised controlled trial (RCT) with 2:1 allocation to the yoga intervention group or minimal active control group. The 2:1 allocation was to ensure there were enough participants to run two classes effectively and gain sufficient qualitative data regarding the intervention's feasibility and acceptability. Concealed random allocation was employed. A statistician independent of the study team generated the random sequence using an online generator [16] (strata: male, female; block size: 3, 6) and randomly allocated participants to groups once the participant was confirmed eligible by the principal investigator following their baseline assessment. Primary and secondary outcomes were assessed before and immediately post-intervention. Participant-blinded and investigator-blinded behavioural intervention was not possible and self-report outcome measures cannot be considered blind.

The study was designed according to SPIRIT guidelines and was conducted in accordance with the principles of Good Clinical Practice. Ethical approval was obtained (HNEHREC 2018/ETH00338) and all participants provided written informed consent. The trial was registered on the Australia New Zealand Clinical Trials Register (ACTRN12618001914257).

\section{Setting}

Study assessments and the yoga intervention were conducted at the Hunter Medical Research Institute, Australia.

\section{Participants}

During a 12-week period (16/11/2018-8/2/2019), participants were recruited via the John Hunter Hospital Department of Respiratory and Sleep Medicine's ambulatory care clinics and research database, and via general/social media advertisement. We included adults ( $\geq 18$ years) with evidence of variable airflow limitation in the last 10 years (bronchodilator response $\geq 12 \%$ or airway hyper-responsiveness or peak flow diary (variation $\geq 15 \%$ or $>50 \mathrm{ml}$ ), and severe asthma according to the European Respiratory Society (ERS)/American Thoracic Society (ATS) taskforce definition [17]: asthma requiring high-dose inhaled corticosteroids $(>1000 \mu \mathrm{g}$ beclomethasone equivalent [18]) with a second controller to prevent uncontrolled disease or disease that remains uncontrolled despite therapy. Detailed inclusion and exclusion are in Additional file 1: Supplementary methods and additional results.

\section{Interventions}

\section{Yoga and mindfulness group}

Detailed information is available in Additional file 1: Supplementary methods and additional results. Briefly, the intervention group participated in two supervised 75-min group classes of yoga and mindfulness per week for 16-weeks in a private room during office hours (up to 8 participants/class), in addition to usual care. An accredited yoga practitioner designed and delivered the programme, in collaboration with the investigator team. Classes focused on increasing movement, controlling breath, and meditation to improve mindfulness, and were designed to be suitable regardless of experience, ability and physical limitations. The instructor explained how to 
perform the exercises, described precautions and encouraged participants to apply the lessons at home. An experienced clinical researcher was present before and after sessions to monitor participant's ability to participate in the class and was on-call in case of adverse events. Participants were advised to self-administer salbutamol before sessions to prevent exercise-induced bronchospasm.

At their first class participants received an activity tracker (Fitbit Charge 2 [Fitbit, Inc], or pedometer for participants without smartphones) and were encouraged to progressively increase their daily steps according to an algorithm [19], up to 10,000 steps/day. Participants were also given information sheets (physical activity guidelines [20], SMART goal-setting [21], exercise and severe asthma [22] and mindfulness [23]), a printed calendar to track their activity goals, and a BORG Dyspnoea Scale [24] to monitor dyspnoea during physical activity.

\section{Control group}

The control group received a minimal physical activity goal-setting intervention supported through telephone contact with an exercise physiologist research officer, in addition to usual care. Participants were mailed their activity tracker, the same printed documents as the yoga group, and a workbook to record goals and progress. During the first call (average 14:27 min), participants set two SMART goals: one regarding daily steps according to an algorithm [19] and another of their choosing regarding physical activity or wellbeing. The research officer called the participant every 2 weeks for 16-weeks (average $7: 17 \mathrm{~min} /$ call) to check on progress toward goals, provide encouragement, and adjust goals if necessary. More information is available in Additional file 1: Supplementary methods and additional results.

\section{Outcome assessment}

\section{Assessments}

Participants underwent face-to-face clinical assessments before randomisation and immediately after the intervention period (16-weeks) to assess primary and secondary outcomes. Additionally, demographic information, asthma duration, smoking history, respiratory and other medication use, and vital signs were assessed at baseline. Participants were telephoned every 3 months up to 9 months post-intervention to assess exacerbations since their last assessment.

\section{Primary outcome}

The pre-specified primary outcome was St George's Respiratory Questionnaire (SGRQ) [25], a valid self-reported health-related quality of life measure in severe asthma [26]. SGRQ describes health-related quality of life globally and in domains symptoms, activity and impact. The minimal clinically important difference is a minus 4-unit change [27].

\section{Secondary outcomes}

Symptom control was assessed via the Asthma Control Questionnaire-5 (ACQ-5) [28]. Past-year moderate and severe exacerbations as described by ERS/ATS guidelines [17] were self-reported. Peripheral blood was collected and analysed for full blood count. Blood serum was analysed for high-sensitivity C-reactive protein (Pathology North, Australia). Fractional exhaled nitric oxide (FeNO) was measured (NIOX VERO). Pre- and post-bronchodilator spirometry (Medigraphics) was completed (Global Lung Initiative predicted values [29]). Body weight and height were measured to calculate body mass index. Percentage body fat and percentage lean muscle mass were analysed by bioimpedance scales (InBody 720). Physical activity intensity and duration, steps per day, and sedentary time were assessed using ActiGraph wGT3X-BT triaxial accelerometers (ActiGraph LLC, Pensacola, FL). Participants wore the accelerometer on their waist $24 \mathrm{~h} /$ day for 8 consecutive days, and data were processed as previously described [3]. Participants completed the 6-min walk test [30] Participants completed self-report measures:

- Pittsburgh Sleep Quality Index [31];

- International Physical Activity Questionnaire-Short Form [32];

- Hospital Anxiety and Depression Scale [33];

- Dyspnoea-12 [34];

- EQ-5D [35] to assess health status;

- Cognitive and Affective Mindfulness Scale-Revised [36]; and

- Friendship Scale [37] to assess social isolation.

Charlson Comorbidity Index [38] was calculated from self-reported medical history.

\section{Adherence}

Attendance was recorded before each yoga session. Control group phone calls were also logged.

\section{Semi-structured interviews}

We invited all participants to a face-to-face semi-structured interview. The interview occurred within 2 months of the intervention with an author who did not deliver the intervention (SAH). Participants were asked open-ended questions from an interview guide about their physical activity, perceived benefits and weaknesses of the intervention, and adherence to the intervention. Interviews were audio-recorded and transcribed verbatim. 


\section{Sample size}

This pilot trial was designed test the study protocol, determine acceptability, and derive outcome effect size data that will inform the sample size calculation for a larger trial [39]. Therefore, no formal power calculation is required [39]. Nevertheless, our initial recruitment target was 54 participants, based on detecting a 6-unit difference in the change in SGRQ between treatment and control groups $(\mathrm{SD}=12$; within-subject $\mathrm{r}=0.8, \alpha=0.05$, $\beta=80 \%$ ). Due to a short 3-month recruitment window that coincided with the Christmas-New Year period, 25 participants were assessed for entry to the study.

\section{Data analysis}

Quantitative analyses were conducted in Stata IC/15 (StataCorp LLC). Data were analysed on intention-totreat basis, including all available data in the analysis. Tests were two-sided with $p<0.05$ considered statistically significant. Descriptive statistics were calculated for demographic and clinical characteristics. Correlation between attendance and SGRQ was calculated for the intervention group. For primary outcome analysis, a restricted maximum likelihood (REML) linear mixed model was conducted, with outcome of SGRQ at baseline and post-treatment assessment, and predictors of treatment condition (intervention vs control), time (baseline vs post-treatment) and their interaction. Given the small sample size and low power to detect interaction effects, planned comparisons examining SGRQ change for each group were conducted. Secondary outcomes were assessed using REML linear mixed models or negative binomial regression for exacerbations. Given this is a pilot trial, analyses focus on confidence interval estimation [39].

Transcribed interview data underwent a manifest qualitative analysis, facilitated with NVivo 12 (QSR International Pty Ltd). Deductive coding was completed, based on the interview schedule. Inductive coding was undertaken concurrently to ensure all content was coded. Codes and themes were discussed by two authors (SAH, $\mathrm{VMcD}$ ). Yoga group interviews were analysed for the current study.

\section{Results}

\section{Recruitment}

During the 12-week recruitment period, 269 potential participants were contacted via telephone or invitation letter (Fig. 1). From this, 25 individuals were assessed: one was ineligible and 24 were randomised. Twenty three participants (96\%) completed the follow-up outcome assessments and 21 (88\%) completed the qualitative interview. The most common reasons for not attending the screening visit were non-response to the invitation letter $(\mathrm{N}=137)$ or being uncontactable via telephone $(\mathrm{N}=26)$. Only 15 reported they were not interested in participating. Among individuals who were interested but said they were unable to participate, reasons were inability to commit to the intervention $(\mathrm{N}=20)$, lived too far away $(\mathrm{N}=12)$, were too unwell $(\mathrm{N}=5)$ or found the schedule of classes unsuitable $(\mathrm{N}=3)$.

\section{Characteristics of participants}

Baseline demographic and clinical characteristics were largely balanced between the intervention and control groups (Table 1), although the control group had later diagnosis of asthma, higher FeNO, greater steps per day, greater self-reported physical activity, greater walk distance and lower anxiety (Table 2). Participants were on average 67 years $(\mathrm{SD}=9)$ and more likely to be female (58\%) than male. Baseline health-related quality of life was impaired (SGRQ $42 \pm 18$ ). Participants completed a median of 4387 (interquartile range 3524, 6732) steps and $14(8,34)$ minutes of moderate-vigorous activity per day, which is below Government recommendations [20].

\section{Attendance}

Participants in the intervention group attended a median of 19.5/32 sessions (range 6-31). Attendance and change in SGRQ during the intervention were not associated $(r=-0.12, p=0.694)$. Control group participants received a median of 9/9 telephone calls (range 7-9).

\section{Intervention efficacy}

For the primary outcome of SGRQ total score, there was no significant interaction between time (baseline vs follow-up) and group (control vs intervention) $(p=0.327)$. This was most likely due to low power. Planned comparisons of each treatment arm separately in the REML model indicated the yoga group had a greater decrease in SGRQ (marginal mean \pm standard error $-9.4 \pm 4.4$, $p=0.032)$ than the control group $(-2.5 \pm 5.5, p=0.647$; Fig. 2a). Examining SGRQ subscales, the greatest mean within-person change was in the Activity domain (Table 2, Fig. 2b-d).

There was little change in most secondary outcomes (Table 2) and no statistically significant interactions between time and treatment group at $p<0.05$, indicating change over time did not differ between groups. The control group slightly worsened in their Dyspnoea-12 scores, whereas the yoga group slightly improved (interaction $p=0.055$; Fig. 3a). Examining the numeric changes in secondary outcomes, some of the most notable results included a reduction in median ACQ-5 in the yoga group compared with the control group (Fig. 3b); increase in 

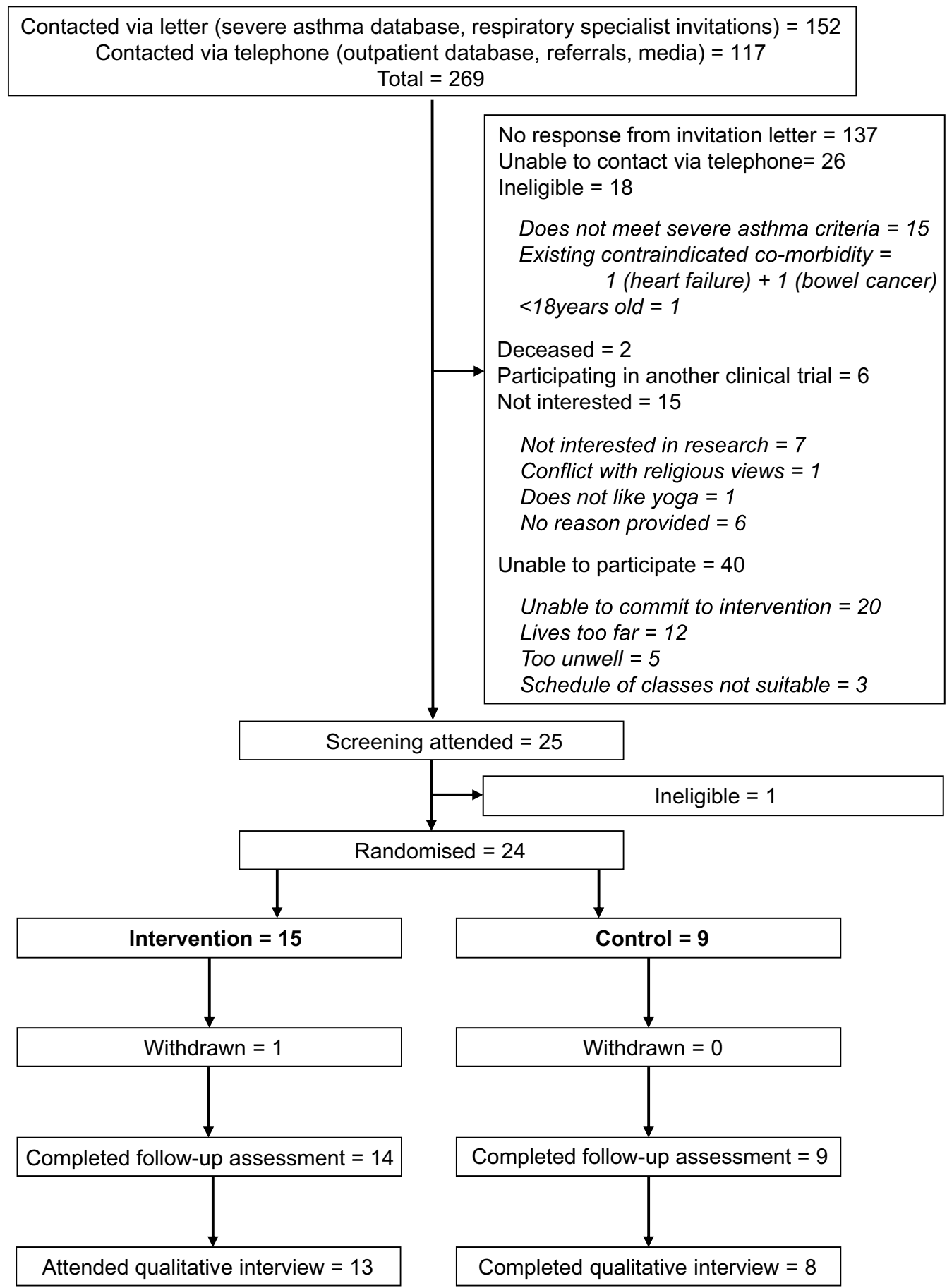

Fig. 1 Flow diagram indicting the number of participants contacted, screened, eligible and completing the study

daily moderate-to-vigorous activity in the control group compared with the yoga group (Fig. 3c); and increase in steps/day in the control group and similar magnitude decrease in the yoga group (Fig. 3d).

\section{Adverse events and safety}

Adverse events in three individuals were suspected to be related to the interventions: shoulder impingement (control); vomiting/nausea/hypertension (yoga); and groin injury (yoga). The two yoga participants ceased 
Table 1 Baseline characteristics

\begin{tabular}{|c|c|c|c|}
\hline & Yoga group & Control group & $p$ \\
\hline N & 15 & 9 & \\
\hline Current age in years, mean (SD) & $67(9)$ & $68(8)$ & 0.86 \\
\hline Female, N (\%) & $9(60 \%)$ & $5(56 \%)$ & 0.83 \\
\hline Employed full- or part-time, N (\%) & $5(33 \%)$ & $3(33 \%)$ & 1.00 \\
\hline Ex-smoker, N (\%) & $5(33 \%)$ & $3(33 \%)$ & 1.00 \\
\hline Age of asthma diagnosis, median (IQR) & $11(3,48)$ & $40(22,45)$ & 0.20 \\
\hline Number of exacerbations in the last 12 months, median (IQR) & $2(1,4)$ & $3(2,3)$ & 0.21 \\
\hline $\mathrm{CCl}$, median (IQR) & $0(0,4)$ & $0(0,2)$ & 0.59 \\
\hline \multicolumn{4}{|l|}{ Current medication use } \\
\hline ICS/LABA, N (\%) & $15(100 \%)$ & $9(100 \%)$ & $\mathrm{N} / \mathrm{A}$ \\
\hline ICS Beclomethasone equivalent dose, median (IQR) & $2000(1000,2000)$ & $2000(1000,2000)$ & 0.36 \\
\hline Biological therapies, N (\%) & $10(67 \%)$ & $7(78 \%)$ & 0.56 \\
\hline LAMA, N (\%) & $8(53 \%)$ & $5(56 \%)$ & 0.92 \\
\hline LTRA, N (\%) & $0(0 \%)$ & $1(11 \%)$ & 0.19 \\
\hline Maintenance oral corticosteroid, N (\%) & $5(33 \%)$ & $2(22 \%)$ & 0.56 \\
\hline
\end{tabular}

CCI Charlson Comorbidity Index, ICS inhaled corticosteroid, IQR interquartile range, LABA long-acting beta-agonist, LAMA long-acting muscarinic antagonists, LTRA leukotriene receptor antagonist, $N$ number, $N / A$ not applicable

the programme after their event. We recorded preand post-BORG dyspnoea ratings for 255 yoga sessions. Generally, there was either no change in ratings $(\mathrm{N}=96)$ or a decrease after yoga $(\mathrm{N}=141)$. Ratings increased on 18 occasions (7\%), which was generally by $0.5(\mathrm{~N}=8)$ or 1 point $(\mathrm{N}=7)$.

\section{Participant experience of the yoga intervention}

Analysis of the qualitative interviews revealed five core themes regarding barriers and facilitators of the yoga intervention: social connection, setting/commitment, changed mindset, addressing breathing and asthma symptoms, and the intersection of different elements (Table 3; Fig. 4; briefly described here and detailed in Additional file 1: Supplementary methods and additional results). Social connection was highly regarded and largely facilitated the experience, specifically through the group-setting, asthma-specific group, connection with an instructor, and connection to the broader community. The setting provided barriers and facilitators pertaining to the structured closed-group programme, holding classes during office hours, and being involved in a research study. These factors increased commitment to attend and built skills yet led to disappointment when participants were unable to attend and may have curtailed ongoing practice beyond the trial. Participants described a changed mindset, which enhanced their experience. Specifically, they reported increased confidence and motivation to be active, an understanding of the value of yoga for asthma, and a more positive outlook. An important aspect for participants was that the programme addressed breathing and asthma symptoms. Most helpful elements were connecting breath with movement, learning relaxation skills for stress reduction, and the yogic breathing exercises reinforcing learnings from breath retraining in other settings. Finally, the intersection between different elements was a key facilitator in addressing multiple health and wellbeing concerns. Participants liked that the classes combined breath, relaxation and movement, and that the overall intervention combined a structured class with use of an activity tracker to motivate beyond class. For many participants, the intervention capitalised on recently improved health status, with the intervention encouraging them to push themselves. Participants reported various health improvements relevant to them; nevertheless, comorbidity sometimes led to negative, typically transient, effects during the yoga, which necessitated modifications to the exercises.

\section{Discussion}

A 16-week yoga and mindfulness programme for people with severe asthma was feasible, acceptable and benefitted health-related quality of life. Although the small sample size limited the ability to detect statistically significant effects, participants in the yoga group significantly improved their health-related quality of life whereas participants in the active control group had no significant improvement. These data can inform larger studies of yoga interventions to assess whether numeric improvements in dyspnoea and asthma control are reliable. Larger studies of interventions involving activity tracking 
Table 2 Group means or medians for secondary outcomes pre- and post-intervention, and mean within-person change in secondary outcomes, with $95 \%$ confidence intervals $(\mathrm{CI})$

\begin{tabular}{|c|c|c|c|c|c|c|}
\hline & \multicolumn{3}{|l|}{ Yoga group } & \multicolumn{3}{|l|}{ Control group } \\
\hline & $\begin{array}{l}\text { Pre, mean/median } \\
\text { (CI) }\end{array}$ & $\begin{array}{l}\text { Post, mean/ } \\
\text { median (CI) }\end{array}$ & $\begin{array}{l}\text { Within-person } \\
\text { change, mean (Cl) }\end{array}$ & $\begin{array}{l}\text { Pre, mean/ } \\
\text { median (CI) }\end{array}$ & $\begin{array}{l}\text { Post, mean/ } \\
\text { median (CI) }\end{array}$ & $\begin{array}{l}\text { Within-person } \\
\text { change, mean (CI) }\end{array}$ \\
\hline \multicolumn{7}{|c|}{ Asthma control and quality of life } \\
\hline ACQ5, median (Cl) & $1.4(0.6,2.0)$ & $0.5(0.2,1.8)$ & $-0.4(-1.0,0.1)$ & $0.8(0.0,2.1)$ & $0.6(0.2,2.2)$ & $0.2(-0.1,0.5)$ \\
\hline $\begin{array}{l}\text { SGRQ_-Total } \\
\text { score, mean (CI) }\end{array}$ & $44(32,55)$ & $35(21,48)$ & $-10(-21,1)$ & $40(29,51)$ & $38(26,49)$ & $-3(-11,6)$ \\
\hline $\begin{array}{l}\text { SGRQ-Activity, } \\
\text { mean (CI) }\end{array}$ & $56(42,70)$ & $46(30,61)$ & $-12(-25,2)$ & $56(32,79)$ & $49(26,72)$ & $-7(-18,5)$ \\
\hline $\begin{array}{l}\text { SGRQ-Symp- } \\
\text { toms, mean (Cl) }\end{array}$ & $48(31,65)$ & $41(23,59)$ & $-8(-22,6)$ & $40(25,55)$ & $46(32,61)$ & $6(-2,15)$ \\
\hline $\begin{array}{l}\text { SGRQ_-Impacts, } \\
\text { mean (CI) }\end{array}$ & $35(24,47)$ & $27(14,40)$ & $-9(-19,0)$ & $31(21,42)$ & $28(17,40)$ & $-3(-16,10)$ \\
\hline $\begin{array}{l}\text { EQ-5D_Your } \\
\text { health today, } \\
\text { median (CI) }\end{array}$ & $80(62,88)$ & $80(61,95)$ & $7(-1,15)$ & $85(67,93)$ & $90(70,95)$ & $1(-7,10)$ \\
\hline $\begin{array}{l}\text { Number of } \\
\text { exacerbations in } \\
\text { the } 12 \text { months } \\
\text { before baseline } \\
\text { assessment } \\
\text { ("pre") or the } \\
\text { duration since } \\
\text { baseline assess- } \\
\text { ment [median } \\
56 \text { weeks] } \\
\text { ("post"), median } \\
(\mathrm{Cl})\end{array}$ & $2(1,3)$ & $1(1,2)$ & $0(-2,2)$ & $3(2,3)$ & $2(1,3)$ & $-1(-3,1)$ \\
\hline \multicolumn{7}{|l|}{ Physical activity } \\
\hline $\begin{array}{l}\text { Actigraph: Steps } \\
\text { per day, mean } \\
\text { (CI) }\end{array}$ & $4883(3749,6017)$ & $3923(2828,5018)$ & $\begin{array}{l}-101(-2073 \\
1871)\end{array}$ & $5652(3367,7937)$ & $6599(3963,9234)$ & $682(-912,2277)$ \\
\hline $\begin{array}{l}\text { Actigraph: Seden- } \\
\text { tary minutes per } \\
\text { day, mean }(\mathrm{Cl})\end{array}$ & $791(656,925)$ & $828(669,986)$ & $-100(-265,65)$ & $792(586,999)$ & $762(569,955)$ & $12(-113,136)$ \\
\hline $\begin{array}{l}\text { Actigraph: Mod- } \\
\text { erate-vigorous } \\
\text { physical activity } \\
\text { mean min/day, } \\
\text { median }(\mathrm{Cl})\end{array}$ & $14(8,31)$ & $17(8,23)$ & $2(-14,18)$ & $14(5,64)$ & $45(15,71)$ & $11(0,21)$ \\
\hline $\begin{array}{l}\text { Actigraph: Light } \\
\text { physical activity } \\
\text { mean min/day, } \\
\text { median }(\mathrm{Cl})\end{array}$ & $161(137,175)$ & $153(102,193)$ & $12(-45,69)$ & $140(124,163)$ & $142(83,168)$ & $-12(-46,23)$ \\
\hline $\begin{array}{l}\text { IPAQ_Metabolic } \\
\text { minutes per } \\
\text { week, median } \\
\text { (Cl) }\end{array}$ & $960(198,1600)$ & $1302(362,2935)$ & $752(81,1423)$ & $2048(105,4073)$ & $2772(747,4916)$ & $1108(-1244,3461)$ \\
\hline \multicolumn{7}{|c|}{ Post-bronchodilator lung function } \\
\hline $\begin{array}{l}\% \text { predicted FEV1, } \\
\text { mean }(\mathrm{Cl})\end{array}$ & $75(61,88)$ & $76(64,88)$ & $3(-3,10)$ & $72(56,87)$ & $73(51,96)$ & $0(-6,6)$ \\
\hline $\begin{array}{l}\% \text { predicted FVC, } \\
\text { mean }(\mathrm{Cl})\end{array}$ & $91(76,105)$ & $92(78,106)$ & $3(-5,11)$ & $90(81,98)$ & $88(74,101)$ & $-1(-10,8)$ \\
\hline FER, mean $(\mathrm{Cl})$ & $0.64(0.57,0.72)$ & $0.65(0.57,0.74)$ & $0.01(-0.02,0.04)$ & $0.62(0.48,0.76)$ & $0.64(0.48,0.80)$ & $0.00(-0.03,0.03)$ \\
\hline \multicolumn{7}{|c|}{ Other physiological outcomes } \\
\hline $\begin{array}{l}\text { Blood eosinophils, } \\
\text { median (Cl) }\end{array}$ & $0.1(0.0,0.2)$ & $0.1(0.0,0.3)$ & $0.0(-0.1,0.0)$ & $0.1(0.0,0.2)$ & $0.1(0.0,0.2)$ & $-0.1(-0.2,0.1)$ \\
\hline FeNO, median $(\mathrm{Cl})$ & $20(10,46)$ & $26(18,45)$ & $1(-5,8)$ & $43(21,91)$ & $36(13,69)$ & $-6(-18,6)$ \\
\hline
\end{tabular}


Table 2 (continued)

\begin{tabular}{|c|c|c|c|c|c|c|}
\hline & \multicolumn{3}{|l|}{ Yoga group } & \multicolumn{3}{|l|}{ Control group } \\
\hline & $\begin{array}{l}\text { Pre, mean/median } \\
\text { (Cl) }\end{array}$ & $\begin{array}{l}\text { Post, mean/ } \\
\text { median (Cl) }\end{array}$ & $\begin{array}{l}\text { Within-person } \\
\text { change, mean (Cl) }\end{array}$ & $\begin{array}{l}\text { Pre, mean// } \\
\text { median (Cl) }\end{array}$ & $\begin{array}{l}\text { Post, mean/ } \\
\text { median (Cl) }\end{array}$ & $\begin{array}{l}\text { Within-person } \\
\text { change, mean (Cl) }\end{array}$ \\
\hline $\begin{array}{l}\text { hs-CRP, median } \\
\text { (CI) }\end{array}$ & $3(1,4)$ & $3(2,5)$ & $1(-1,3)$ & $1(1,10)$ & $4(1,9)$ & $-6(-26,13)$ \\
\hline $\mathrm{BMI}$, mean $(\mathrm{Cl})$ & $32(28,35)$ & $32(29,35)$ & $0(-1,1)$ & $29(24,34)$ & $29(24,35)$ & $0(0,1)$ \\
\hline $\begin{array}{l}\text { BIA \% body fat } \\
\text { mass, mean }(\mathrm{Cl})\end{array}$ & $41(35,47)$ & $42(37,48)$ & $1(0,2)$ & $37(26,47)$ & $38(28,47)$ & $1(0,2)$ \\
\hline $\begin{array}{l}\text { Total walk dis- } \\
\text { tance, mean (Cl) }\end{array}$ & $436(384,488)$ & $453(392,513)$ & $33(-2,67)$ & $526(424,628)$ & $546(441,652)$ & $20(-40,80)$ \\
\hline \multicolumn{7}{|c|}{ Other patient reported outcomes } \\
\hline $\begin{array}{l}\text { Dyspnea-12- } \\
\text { total score (high } \\
\text { score is greater } \\
\text { symptoms), } \\
\text { mean }(\mathrm{Cl})\end{array}$ & $11(6,15)$ & $9(3,15)$ & $-4(-8,1)$ & $7(2,13)$ & $10(4,17)$ & $4(-2,9)$ \\
\hline $\begin{array}{l}\text { HADS Anxiety } \\
\text { score (high } \\
\text { score is greater } \\
\text { symptoms), } \\
\text { median (Cl) }\end{array}$ & $6(4,9)$ & $6(2,10)$ & $-1(-3,1)$ & $4(0,7)$ & $4(2,7)$ & $0(-2,2)$ \\
\hline $\begin{array}{l}\text { HADS Depres- } \\
\text { sion score (high } \\
\text { score is greater } \\
\text { symptoms), } \\
\text { median }(\mathrm{Cl})\end{array}$ & $3(3,8)$ & $5(1,8)$ & $-1(-2,0)$ & $4(1,8)$ & $1(0,6)$ & $-1(-2,0)$ \\
\hline $\begin{array}{l}\text { Pittsburgh Sleep } \\
\text { Quality Index } \\
\text { total (high score } \\
\text { is poorer sleep } \\
\text { quality), mean } \\
\text { (Cl) }\end{array}$ & $8(6,9)$ & $8(5,10)$ & $-1(-3,2)$ & $7(5,9)$ & $5(3,7)$ & $-1(-4,1)$ \\
\hline $\begin{array}{l}\text { Friendship Assess- } \\
\text { ment total score } \\
\text { (high score is } \\
\text { less social isola- } \\
\text { tion), median } \\
\text { (Cl) }\end{array}$ & $20(18,24)$ & $20(16,22)$ & $-1(-4,1)$ & $23(13,24)$ & $21(17,24)$ & $-1(-4,2)$ \\
\hline $\begin{array}{l}\text { CAMS-R total } \\
\text { score (high } \\
\text { score is more } \\
\text { mindfulness), } \\
\text { median (Cl) }\end{array}$ & $33(29,35)$ & $34(28,37)$ & $2(-1,5)$ & $34(21,38)$ & $37(30,40)$ & $4(-2,10)$ \\
\hline
\end{tabular}

ACQ-5 Asthma Control Questionnaire-5, BIA bioimpedance analysis, BMI body mass index, CAMS-R Cognitive and Affective Mindfulness Scale - Revised, $C I$ confidence interval, FeNO fractional exhaled nitric oxide, FER forced expiratory ratio, FEV 1 forced expiratory volume in $1 \mathrm{~s}$, FVC forced vital capacity, HADS Hospital Anxiety and Depression Scale, $h s-C R P$ high sensitivity C-reactive protein, IPAQ International Physical Activity Questionnaire, SGRQ St George's Respiratory Questionnaire

and goal-setting may also confirm whether physical activity improvements observed in the control group are reliable. When considering how to test and implement exercise interventions for people with severe asthma into the future, qualitative interviews highlighted the following potentially important components: forming social connections, an appropriate setting/structure, changing mindsets, addressing breathing and asthma symptoms, and combining multiple elements into one intervention package.
Participants reported impaired health-related quality of life at baseline, which improved for participants in the yoga group. The SGRQ Activity subscale shifted most. This subscale characterises activities that are caused or limited by breathlessness. The quantitative findings also suggested numeric (although small) improvements in dyspnoea and asthma control in the intervention group, relative to the control group. Previous studies in generally mild-to-moderate asthma similarly indicate that yoga improves health-related quality of life [13-15]. In studies of asthma and other diseases, yoga has also improved 

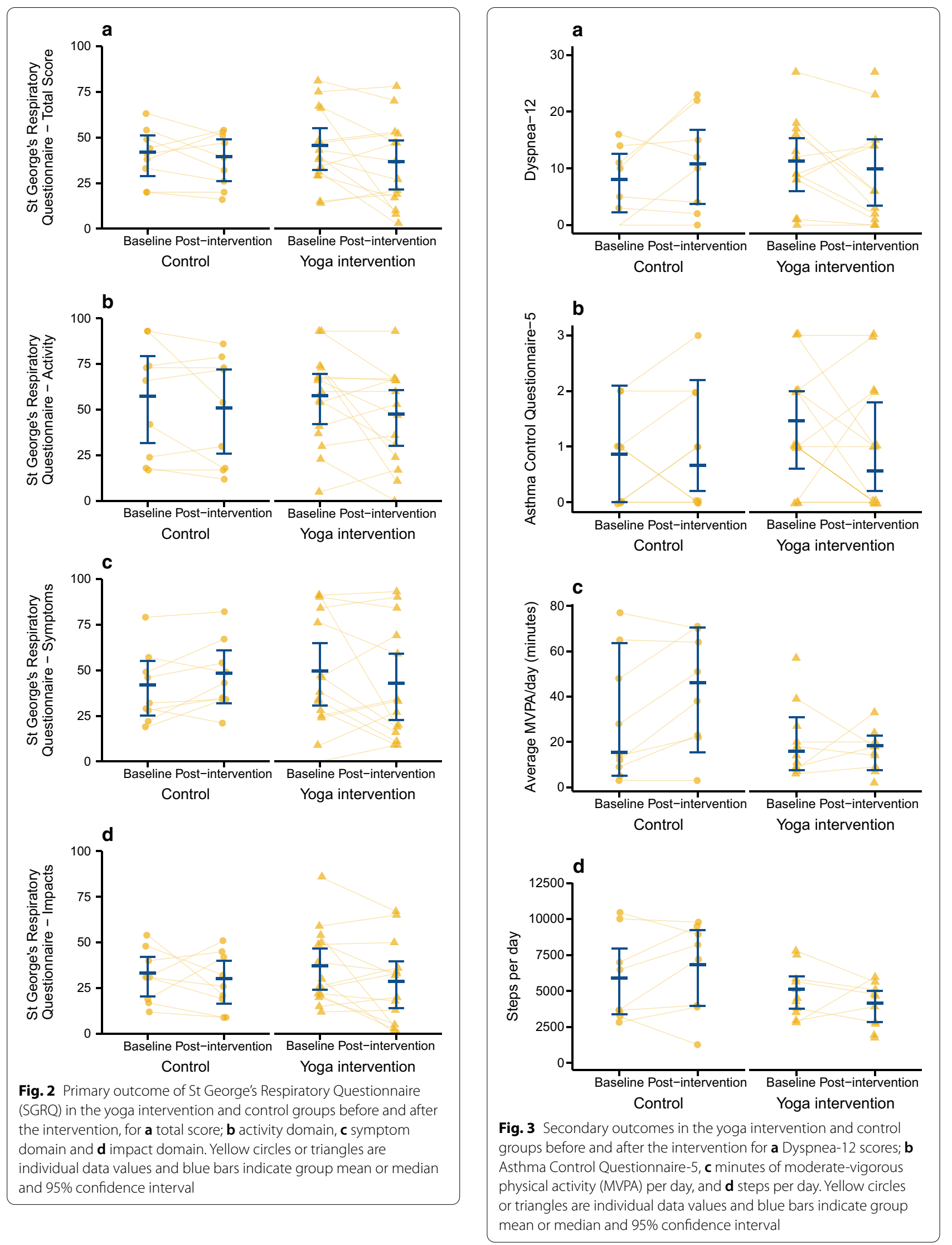


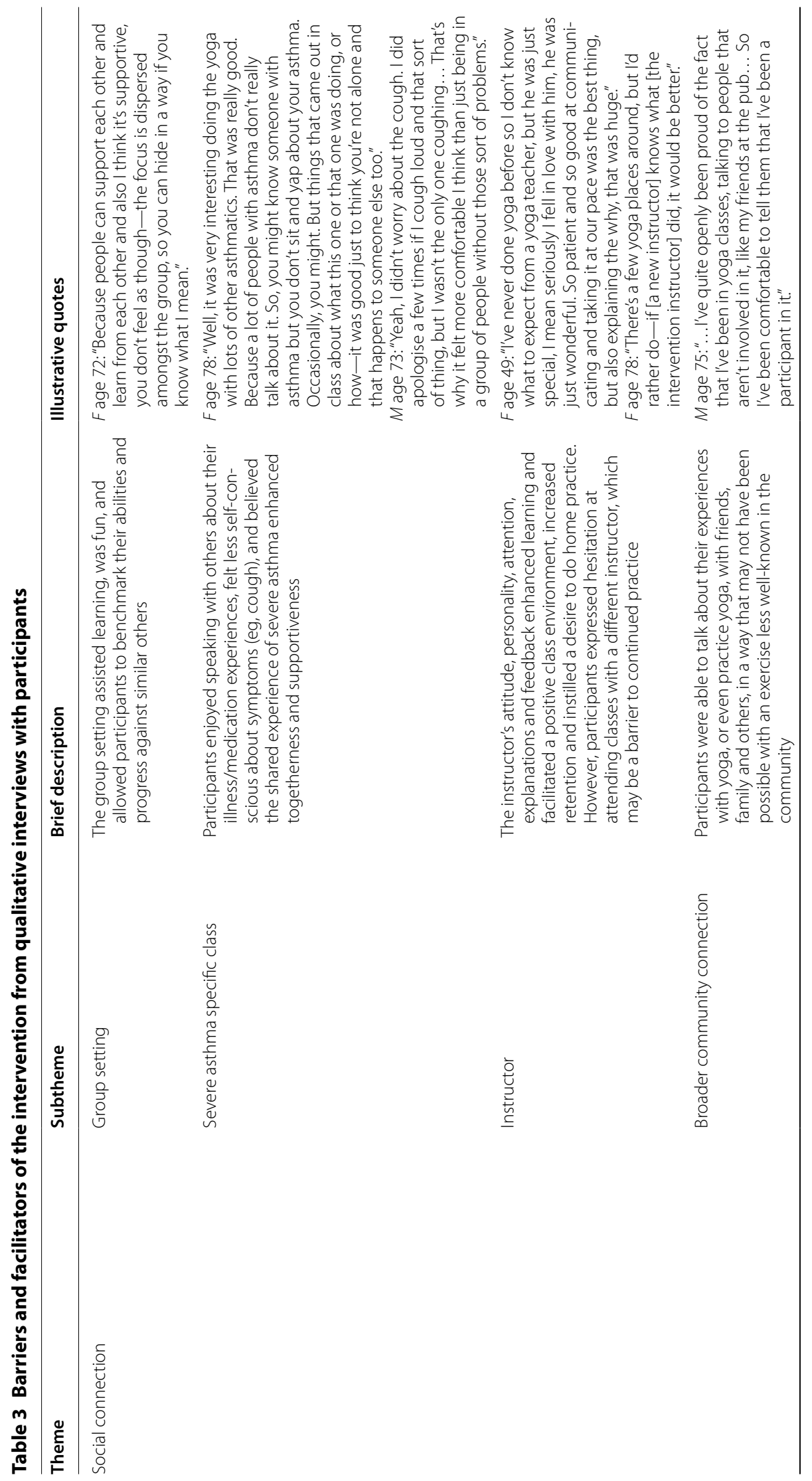




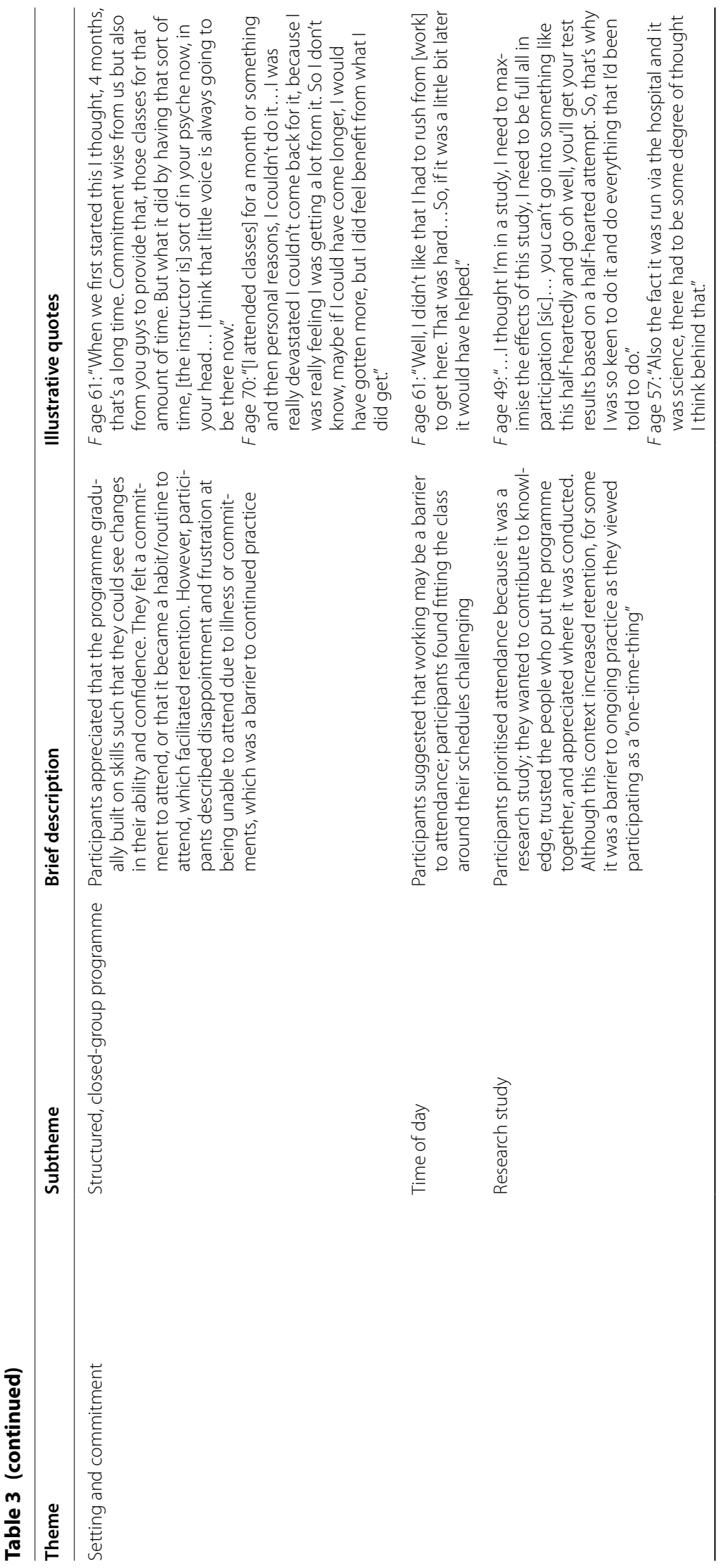




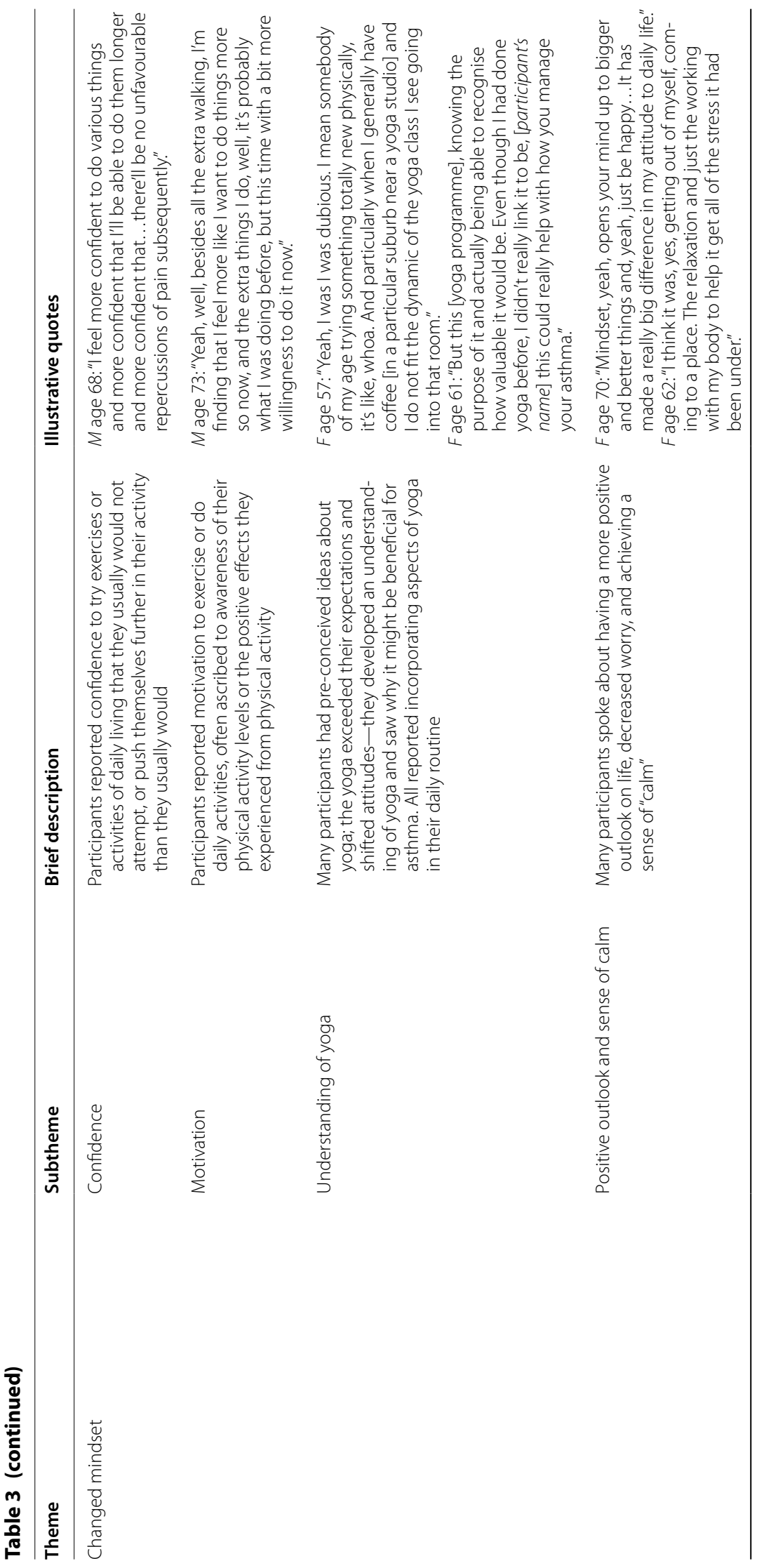




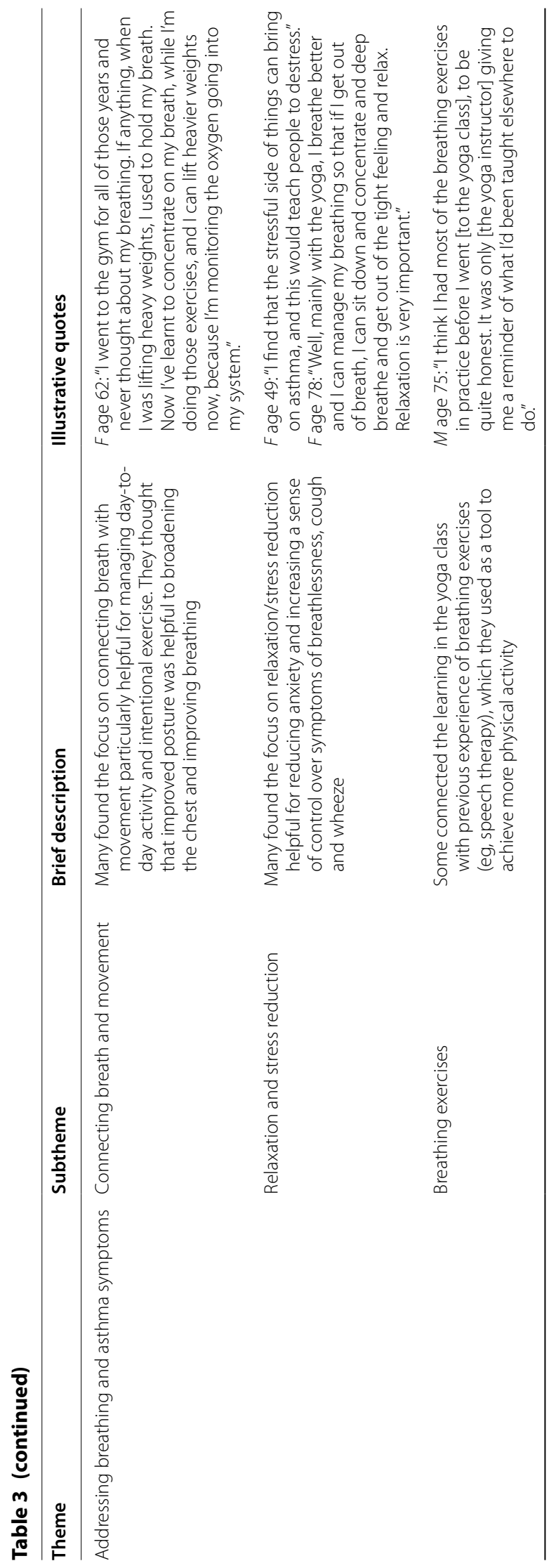




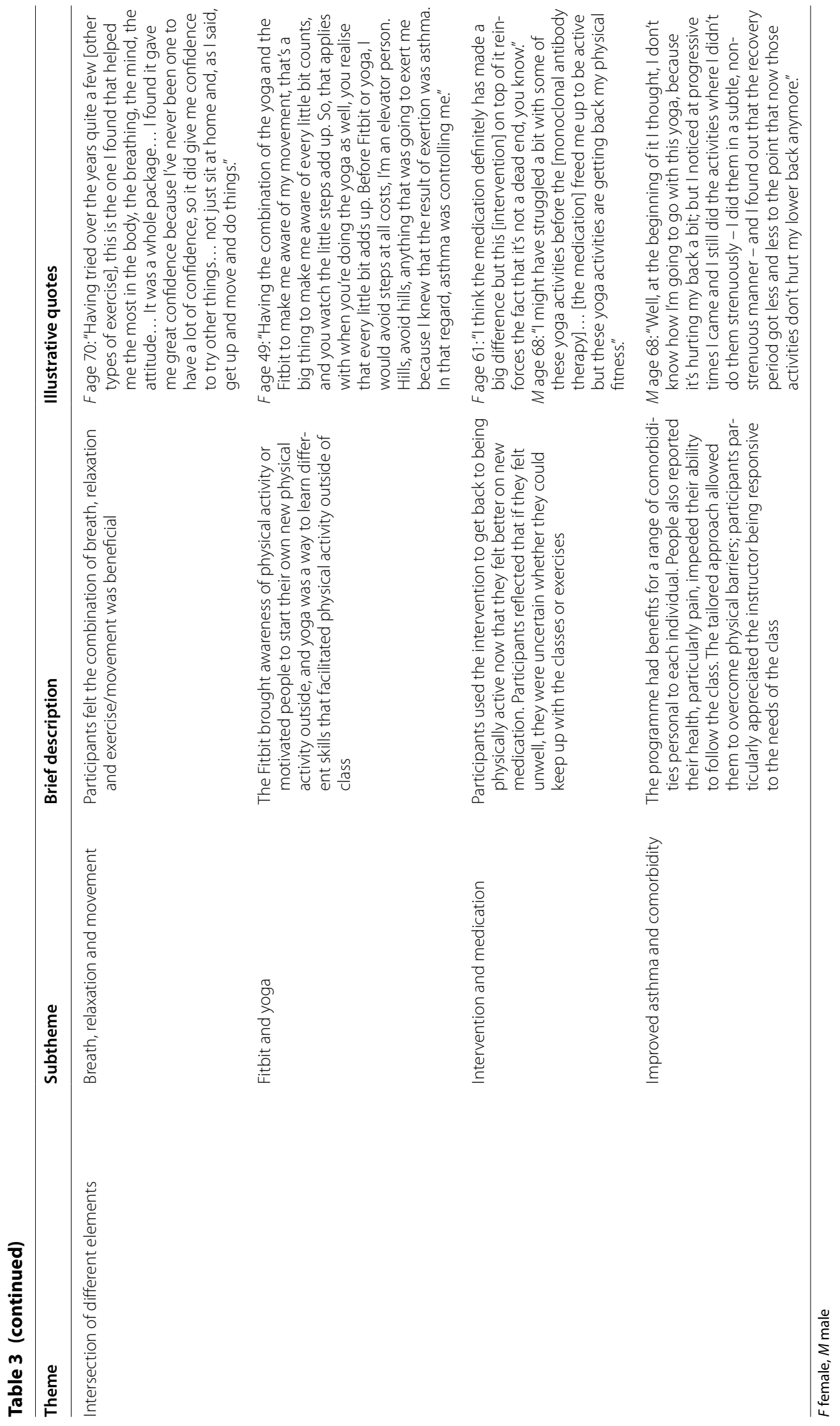




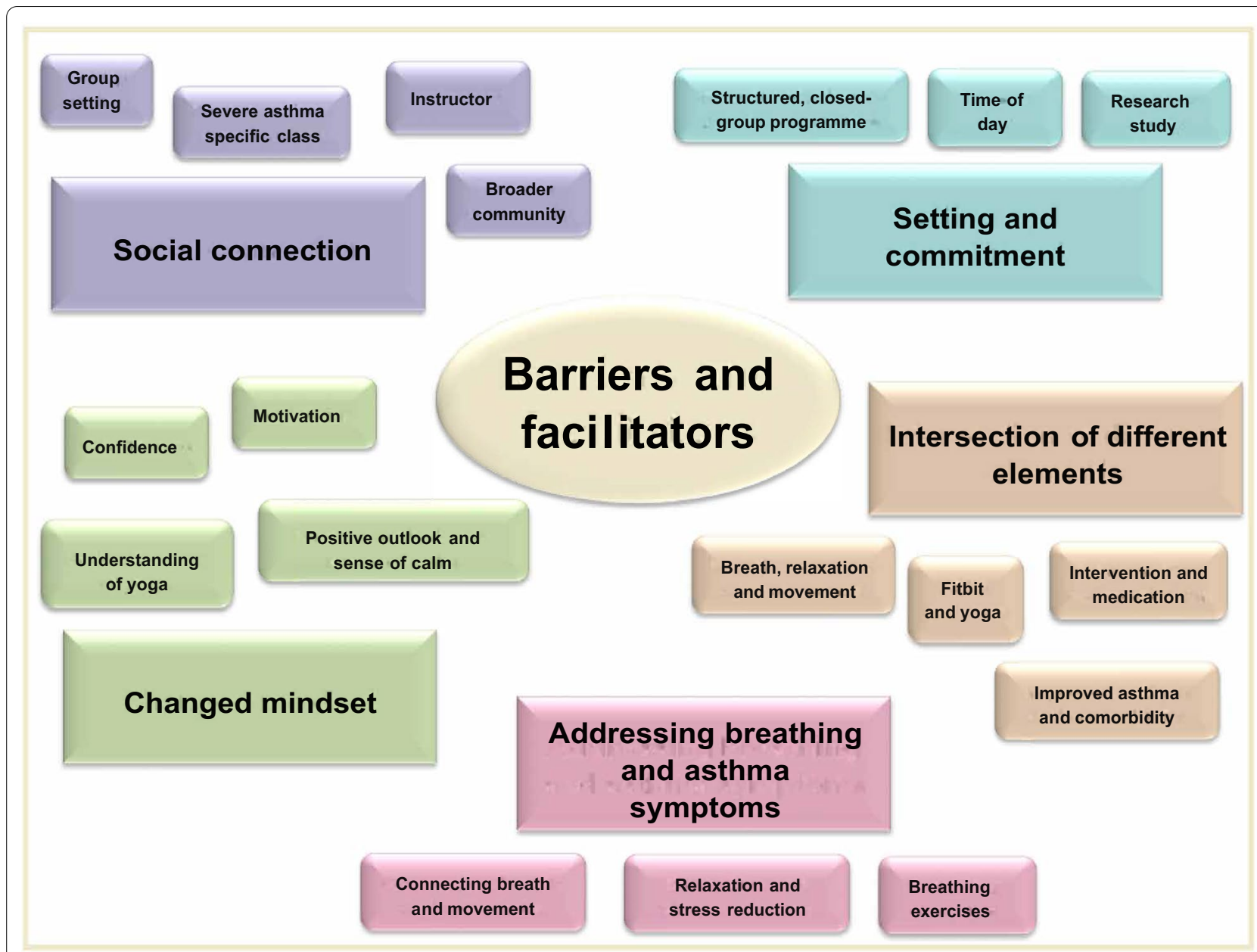

Fig. 4 Summary of themes regarding barriers and facilitators of the intervention

exercise capacity, physical limitation, fatigue, breathlessness, strength, mental health, and social connectedness [13-15, 40-44]. Consistent with the quantitative findings, participants described health and wellbeing benefits during the qualitative interviews, particularly in their breathing and ability/motivation to be active during daily life. Participants identified the most helpful components to improve breathing were learning to connect breath with movement, stress-reducing relaxation skills, and yogic breathing exercises. A change in mindset, namely increased confidence, motivation and understanding of how yoga may benefit their asthma, helped improve their perceived activity levels. However, quantitative physical activity values did not increase and steps/day decreased, possibly because low-intensity yoga displaced more active exercise or participants were prioritising relaxation activities. Participants who dropped out of the intervention due to injury or illness may have also contributed lower post-intervention activity levels.
Contrary to the hypothesis, there was little change in most secondary outcomes in the yoga group. However, considering the qualitative findings, this may be because changes were idiosyncratic to individuals. A subtheme that emerged was that the participants reported a range of health improvements that were relevant to them, including pain, cough, sleep, fatigue and wellbeing.

There was no statistically or clinically significant change in SGRQ for the control group, yet group median moderate-vigorous physical activity increased from 14 to $44 \mathrm{~min} /$ day (average within-person increase of $11 \mathrm{~min}$ ) and within-person step-count increased by 682 steps/ day. Thus, perhaps interventions that increase physical activity alone may be insufficient for improving multifaceted outcomes such as health-related quality of life. Nevertheless, generally physical activity is positively correlated with good mental and physical health [45]. Very few studies characterise physical activity in people with severe asthma objectively. We recently published the first objective evidence that people with severe asthma walk 
over 2000 fewer steps/day than healthy controls, reaching only 5362 steps/day, and record a median of $22 \mathrm{~min} /$ day of moderate-vigorous physical activity [3]. In the current study, the control group recorded $44 \mathrm{~min} /$ day postintervention. Therefore, participants were on average achieving above national guidelines of $150 \mathrm{~min}$ of moderate-vigorous activity/week [20]. Achieving national benchmarks for physical activity is therefore feasible for people with severe asthma. Using an activity tracker alongside coaching toward a step goal may be an effective way to increase physical activity in people with severe asthma and should be explored.

In terms of feasibility and acceptability, this was a twice-a-week, closed-group programme of yoga delivered over 16-weeks. It was designed to be suitable regardless of experience and physical limitations, with the exercises supervised and modified as required. Participants appreciated modifications the instructor made and the "gentle", "achievable" nature of the exercise. The classes did not increase dyspnoea and resulted in few adverse events, highlighting this as a feasible exercise for people with severe asthma. Participants reported that the structure facilitated the experience, allowing them to gradually build skills and providing a sense of commitment that they found motivating. Nevertheless, the structure was limiting for people who worked, were unwell or injured, or had unexpected commitments arise during the programme. Participants completed a median of $19.5 / 32$ sessions. During interviews participants expressed disappointment and frustration at being unable to attend the programme. Among individuals approached for the study, being unable to commit to the intervention was a common reason for not participating. These are important considerations for designing feasible exercise interventions, highlighting a need to balance providing a sense of commitment with a programme flexible enough to accommodate a diverse and sometimes unwell population.

There were two other important considerations relevant to developing and implementing exercise interventions for people with severe asthma. Firstly, participants appreciated the social connection the intervention provided. Social connection and norming are a wellestablished stimulators of health behaviour change [46]. Secondly, participants appreciated the intersection between multiple components. For example, combining breath, movement and relaxation during the yoga classes, combining an exercise class with an activity tracker for outside class, and combining an exercise intervention with their severe asthma health care. The desirability for and benefits of a "package" of different elements has been described in other qualitative work regarding preferences for medication models of care in severe asthma [47].

There are several limitations to consider when interpreting these findings. Firstly, this was a small pilot trial designed to assess feasibility and acceptability, inform future studies and aid implementation into practice. Low sample size reduced our power to detect statistically significant effects, such that the primary outcome effect was only detected through planned comparisons. A larger sample size would increase power and verify whether the findings are robust. Further a future study should also include longer term follow up in a larger sample to determine the maintenance of effect. Nevertheless this study remains important, as there are few studies that have tested physical activity interventions specifically in a severe asthma population. The strengths of this study are the combination of the quantitative assessments in two active intervention groups, and the rich qualitative data that informs patient acceptability and preferences. These data should be used to inform future severe asthma physical activity RCTs. We acknowledge that behavioural interventions, such as the current intervention, performed unblinded using volunteers are subject to selection and measurement bias. Participants entered the study knowing the intervention was a yoga trial, which may have led to selection bias in the type of participants who volunteered. Furthermore, participants knew their group allocation, which may have led to bias in participant response to outcome questionnaires. To reduce these risks, we ensured both groups were informed that the effect of this intervention is unknown, and that true equipoise exists. The patient information statement was presented objectively to reflect the current evidence. To reduce the chances of contamination between arms, scheduled appointments for the control and intervention groups were on different days.

A yoga and mindfulness intervention is feasible, acceptable and improved health-related quality of life for people with severe asthma. These data are useful in informing larger RCTs to appropriately test the efficacy of the approach. From the patient's perspective, exercise interventions for people with severe asthma may benefit from incorporating opportunities for social connection, having a flexible programme structure, incorporating a shift in mindset, addressing breathing and asthma symptoms, and having multiple synergistic components. Studies to improve physical activity among people with severe asthma are needed, and this study is important in informing the design of future research. 


\section{Supplementary Information}

The online version contains supplementary material available at https://doi. org/10.1186/s12890-021-01436-3.

Additional file 1. Supplementary methods and additional results.

\section{Abbreviations}

ACQ: Asthma Control Questionnaire; ATS: American Thoracic Society; COPD: Chronic obstructive pulmonary disease; ERS: European Respiratory Society; FeNO: Fractional exhaled nitric oxide; RCT: Randomised controlled trial; REML: Restricted maximum likelihood; SD: Standard deviation; SGRQ: St George's Respiratory Questionnaire.

\section{Acknowledgements}

Not applicable.

\section{Authors' contributions}

All authors contributed to data interpretation and critical review of the manuscript. VMM conceived the study and developed the research question. VMM, SAH, PGG and PDU contributed to developing the study design and study protocol. PDU recruited patients, conducted outcome assessments and conducted the control intervention. AB developed and conducted the yoga intervention. VMM and PGG reviewed patient eligibility, safety and progress. $\mathrm{SAH}$ conducted qualitative interviews, analysed quantitative and qualitative data and drafted the manuscript. All authors read and approved the final manuscript.

\section{Funding}

This study was supported by a John Hunter Charitable Trust grant. The funder was not involved in data collection, analysis, or interpretation; trial design; patient recruitment; or any aspect pertinent to the study.

\section{Availability of data and materials}

The datasets used and/or analysed during the current study are available from the corresponding author on reasonable request.

\section{Ethics approval and consent to participate}

Ethical approval was obtained from the Hunter New England Human Research Ethics Committee (2018/ETH00338) and all participants provided written informed consent. Guidelines and Regulations: All methods were carried out in accordance with relevant guidelines and regulations.

\section{Consent for publication}

Not applicable.

\section{Competing interests}

SAH salary has been supported by grants from GlaxoSmithKline and AstraZeneca paid to her employer (University of Newcastle) for unrelated work. PDU reports no competing interests. $A B$ receives income from yoga instruction. PGG has received research grants and speaker fees from AstraZeneca, GlaxoSmithKline and Novartis. VMM has received speaker fees for unrelated work, grants for organising education for unrelated work, and research funds for unrelated work from AstraZeneca, Menarini and GlaxoSmithKline.

\section{Author details}

${ }^{1}$ Centre of Excellence in Severe Asthma and Priority Research Centre for Healthy Lungs, University of Newcastle, University Drive, Callaghan, NSW 2308, Australia. ${ }^{2}$ Department of Respiratory and Sleep Medicine, John Hunter Hospital, New Lambton Heights, NSW, Australia. ${ }^{3}$ Yoga For All, Newcastle, NSW, Australia.

Received: 5 November 2020 Accepted: 9 February 2021

Published online: 27 February 2021

\section{References}

1. McDonald VM, Hiles SA, Godbout K, Harvey ES, Marks GB, Hew M, et al. Treatable traits can be identified in a severe asthma registry and predict future exacerbations. Respirology. 2019;24(1):37-47.

2. Cordova-Rivera L, Gibson PG, Gardiner PA, McDonald VM. A systematic review of associations of physical activity and sedentary time with asthma outcomes. J Allergy Clin Immunol Pract. 2018;6(6):1968-81.

3. Cordova-Rivera L, Gibson PG, Gardiner PA, Powell H, McDonald VM. Physical activity and exercise capacity in severe asthma: key clinical associations. J Allergy Clin Immunol Pract. 2018;6(3):814-22.

4. Hiles SA, Lamers F, Milaneschi Y, Penninx BWJH. Sit, step, sweat: Longitudinal associations between physical activity patterns, anxiety and depression. Psychol Med. 2017;47(8):1466-77.

5. Australian Institute of Health and Welfare. Chronic respiratory diseases in Australia. Canberra: AlHW; 2005.

6. Lee IM, Shiroma EJ, Lobelo F, Puska P, Blair SN, Katzmarzyk PT. Effect of physical inactivity on major non-communicable diseases worldwide: an analysis of burden of disease and life expectancy. The Lancet. 2012;380(9838):219-29.

7. Avallone KM, McLeish AC. Asthma and aerobic exercise: a review of the empirical literature. J Asthma. 2013;50(2):109-16.

8. França-Pinto A, Mendes FAR, de Carvalho-Pinto RM, Agondi RC, Cukier A, Stelmach $\mathrm{R}$, et al. Aerobic training decreases bronchial hyperresponsiveness and systemic inflammation in patients with moderate or severe asthma: a randomised controlled trial. Thorax. 2015;70(8):732-9.

9. Waschki B, Kirsten A, Holz O, Muller KC, Meyer T, Watz H, et al. Physical activity is the strongest predictor of all-cause mortality in patients with COPD: a prospective cohort study. Chest. 2011;140(2):331-42.

10. Winn CON, Mackintosh KA, Eddolls WTB, Stratton G, Wilson AM, Rance JY, et al. Perceptions of asthma and exercise in adolescents with and without asthma. J Asthma. 2017;55(8):868-76.

11. Butterfield N, Schultz T, Rasmussen P, Proeve M. Yoga and mindfulness for anxiety and depression and the role of mental health professionals: a literature review. J Mental Health Train Educ Pract. 2017;12(1):44-54.

12. Chu P, Gotink RA, Yeh GY, Goldie SJ, Hunink MM. The effectiveness of yoga in modifying risk factors for cardiovascular disease and metabolic syndrome: a systematic review and meta-analysis of randomized controlled trials. Eur J Prevent Cardiol. 2016;23(3):291-307.

13. Cramer H, Posadzki P, Dobos G, Langhorst J. Yoga for asthma: a systematic review and meta-analysis. Ann Allergy Asthma Immunol. 2014;112(6):50310.e5.

14. Paudyal P, Jones $C$, Grindey C, Dawood R, Smith H. Meditation for asthma: systematic review and meta-analysis. J Asthma. 2017;55:771-8.

15. Yang Z-Y, Zhong H-B, Mao C, Yuan J-Q, Huang Y-F, Wu X-Y, et al. Yoga for asthma. Cochrane Database Syst Rev. 2016;Issue 4: Art. No.: CD010346.

16. Sealed Envelope Ltd. Simple randomisation service 2018. https://www. sealedenvelope.com/simple-randomiser/v1/. Accessed 8 Nov 2018.

17. Chung KF, Wenzel SE, Brozek JL, Bush A, Castro M, Sterk PJ, et al. International ERS/ATS guidelines on definition, evaluation and treatment of severe asthma. Eur Respir J. 2014;43(2):343-73.

18. Global Initiative for Asthma. Global Strategy for Asthma Management and Prevention Fontana, USA: Global Initiative for Asthma; 2019. https:// ginasthma.org/gina-reports/. Accessed 24 Nov 2019.

19. Mendoza L, Horta P, Espinoza J, Aguilera M, Balmaceda N, Castro A, et al. Pedometers to enhance physical activity in COPD: a randomised controlled trial. Eur Respir J. 2015;45(2):347-54.

20. Australian Government Department of Health. Australia's Physical Activity and Sedentary Behaviour Guidelines for Adults Canberra, Australia: Commonwealth of Australia; 2014. https://www1.health.gov.au/internet/ main/publishing.nsf/Content/health-pubhlth-strateg-phys-act-guidelines \#npa1864. Accessed 14 Jan 2019.

21. LiveLighter. Factsheet-Goal Setting Subiaco, Australia: LiveLighter; 2018. https://livelighter.com.au/Tools-and-Resources/Resources. Accessed 14 Jan 2019. 
22. Asthma UK. Exercising when you have severe asthma London, UK: Asthma UK; 2016. www.asthma.org.uk/advice/severe-asthma/makin g-life-easier-severe-asthma/exercising-when-you-have-severe-asthma/. Accessed 14 Jan 2019

23. ReachOut Australia. How to practise mindfulness Pyrmont, Australia: ReachOut Australia; 2018. http://au.reachout.com/articles/how-to-pract ise-mindfulness. Accessed 14 Jan 2019.

24. Borg GAV. Psychophysical bases of perceived exertion. Med Sci Sports Exerc. 1982;14(5):377-81.

25. Jones PW, Quirk FH, Baveystock CM, Littlejohns P. A self-complete measure of health status for chronic airflow limitation: The St. George's Respiratory Questionnaire. Am Rev Respir Dis. 1992;145(6):1321-7.

26. Nelsen LM, Kimel M, Murray LT, Ortega H, Cockle SM, Yancey SW, et al. Qualitative evaluation of the St George's Respiratory Questionnaire in patients with severe asthma. Respir Med. 2017;126:32-8.

27. Jones PW. Interpreting thresholds for a clinically significant change in health status in asthma and COPD. Eur Respir J. 2002;19(3):398.

28. Juniper EF, Svensson K, Mörk AC, Ståhl E. Measurement properties and interpretation of three shortened versions of the asthma control questionnaire. Respir Med. 2005:99(5):553-8.

29. Quanjer PH, Stanojevic S, Cole TJ, Baur X, Hall GL, Culver BH, et al. Multiethnic reference values for spirometry for the 3-95-yr age range: the Global Lung Function 2012 equations. Eur Respir J. 2012;40(6):1324-43.

30. Holland AE, Spruit MA, Troosters T, Puhan MA, Pepin V, Saey D, et al. An official European Respiratory Society/American Thoracic Society technical standard: Field walking tests in chronic respiratory disease. Eur Respir J. 2014;44(6):1428-46.

31. Buysse DJ, Reynolds CF, MonkTH, Berman SR, Kupfer DJ. The Pittsburgh sleep quality index: a new instrument for psychiatric practice and research. Psychiatry Res. 1989;28(2):193-213.

32. Craig CL, Marshall AL, Sjöström M, Bauman AE, Booth ML, Ainsworth BE, et al. International physical activity questionnaire: 12-country reliability and validity. Med Sci Sports Exerc. 2003;35(8):1381-95.

33. Zigmond AS, Snaith RP. The Hospital Anxiety and Depression Scale. Acta Psychiatr Scand. 1983;67(6):361-70.

34. Yorke J, Moosavi SH, Shuldham C, Jones PW. Quantification of dyspnoea using descriptors: development and initial testing of the Dyspnoea-12. Thorax. 2010;65(1):21-6.

35. The EuroQol Group. EuroQol-a new facility for the measurement of health-related quality of life. Health Policy. 1990;16(3):199-208.

36. Feldman G, Hayes A, Kumar S, Greeson J, Laurenceau JP. Mindfulness and emotion regulation: the development and initial validation of the Cognitive and Affective Mindfulness Scale-Revised (CAMS-R). J Psychopathol Behav Assess. 2007:29(3):177-90.
37. Hawthorne G. Measuring social isolation in older adults: development and initial validation of the friendship scale. Soc Indic Res. 2006;77(3):521-48

38. Charlson ME, Pompei P, Ales KL, MacKenzie CR. A new method of classifying prognostic comorbidity in longitudinal studies: development and validation. J Chronic Dis. 1987;40(5):373-83.

39. Lancaster DS, Williamson PR. Design and analysis of pilot studies: recommendations for good practice. J Eval Clin Pract. 2004;10:307-12.

40. Kiecolt-Glaser JK, Bennett JM, Andridge R, Peng J, Shapiro CL, Malarkey WB, et al. Yoga's impact on inflammation, mood, and fatigue in breast cancer survivors: a randomized controlled trial. J Clin Oncol. 2014;32(10):1040-9.

41. Pascoe MC, Thompson DR, Ski CF. Yoga, mindfulness-based stress reduction and stress-related physiological measures: a meta-analysis. Psychoneuroendocrinology. 2017;86:152-68.

42. Pullen PR, Nagamia SH, Mehta PK, Thompson WR, Benardot D, Hammoud $R$, et al. Effects of Yoga on inflammation and exercise capacity in patients with chronic heart failure. J Cardiac Fail. 2008;14(5):407-13.

43. Saxena T, Saxena M. The effect of various breathing exercises (pranayama) in patients with bronchial asthma of mild to moderate severity. Int J Yoga. 2009;2(1):22-5.

44. Bahçecioğlu Turan G, Tan M. The effect of yoga on respiratory functions, symptom control and life quality of asthma patients: a randomized controlled study. Complement Ther Clin Pract. 2020;38:101070.

45. Penedo FJ, Dahn JR. Exercise and well-being: A review of mental and physical health benefits associated with physical activity. Curr Opin Psychiatry. 2005;18(2):189-93.

46. Carey RN, Connell LE, Johnston M, Rothman AJ, de Bruin M, Kelly MP, et al. Behavior change techniques and their mechanisms of action: a synthesis of links described in published intervention literature. Ann Behav Med. 2019:53(8):693-707.

47. Clark VL, Gibson PG, McDonald VM. The experience of people with severe asthma prescribed add-on pharmacotherapies. J Asthma Allergy. 2021 (In press).

\section{Publisher's Note}

Springer Nature remains neutral with regard to jurisdictional claims in published maps and institutional affiliations.
Ready to submit your research? Choose BMC and benefit from:

- fast, convenient online submission

- thorough peer review by experienced researchers in your field

- rapid publication on acceptance

- support for research data, including large and complex data types

- gold Open Access which fosters wider collaboration and increased citations

- maximum visibility for your research: over 100M website views per year

At $\mathrm{BMC}$, research is always in progress.

Learn more biomedcentral.com/submissions 